\title{
The use of rice bran oil within a biorefinery concept
}

\author{
Federica Zaccheria, Matteo Mariani and Nicoletta Ravasio*
}

\begin{abstract}
Background: A waste of the rice production chain, namely bran, can be used to produce an oil with a very high content in free fatty acids (FFA). Due to its very high acidity, this material cannot be used neither to feed power generators nor as raw material for oleochemicals synthesis, and therefore it is not even extracted.

Results: Rice bran oil with a content of $84 \%$ in free fatty acids can be converted into a mixture of triglycerides or into useful oleochemicals such as monoglycerides, widely used as emulsifiers in food. Monoglycerides were obtained carrying out a one step esterification + transesterification reaction over an amorphous solid acid. Yields are higher than those obtained by enzymatic transesterification of oil and competitive with the esterification of free fatty acids involving the use of homogeneous acids generating significant amounts of wastewaters. On the other hand, esterification with higher amount of glycerol, a low value by-product of the biodiesel industry, gave an oil with low acidity suitable to feed power generators.
\end{abstract}

Conclusions: The use of solid acid catalysts is a valuable tool for the valorization of rice bran oil. The chance to produce a low acidity oil or monoglycerides in one step from RBO may add value to the whole rice productive chain while setting the stage for the design of biorefineries based on the use of agro-industrial residues.

Keywords: Biorefinery, Waste valorization, Monoglycerides, Rice bran oil, Acidic oils

\section{Background}

The transition to a low-carbon, resource-efficient, safe and sustainable economy is more and more urgent as well as the transition from a linear economy model, where raw materials are transformed into products and wastes are disposed of, to a circular economy one, where all residues and wastes are recycled, reused or upgraded. The valorization of residues and wastes of the food productive chain is well inserted in this scenario [1,2].

Thus, the production of food generates huge amount of residues and wastes like straws, milk whey and fruit pomace just to mention a few. Currently these wastes are processed in animal feed, for the production of compost and fertilizer or anaerobically digested to biogas. In this way most of their potential is lost [3].

*Correspondence: n.ravasio@istm.cnr.it

CNR Institute of Molecular Science and Technology, Via Golgi 19, 20133 Milan, Italy
On the contrary, to add value to these residues by exploiting their chemical structure to obtain bio-products or bio-materials appears as a more interesting and sustainable approach. By doing so, we will pave the way for both bio-based and circular economy without interfering with the food versus feed issue.

Rice is the agricultural commodity with the thirdhighest worldwide production and is the staple food for a large part of the world population. However, its production generates a huge amount of wastes and residues.

In particular, rice bran is a significant residue of white rice processing, being the stream of the milling step in the rice manufacturing. Together with rice husk it accounts for $20 \%$ of the overall amount of the processed crop, that means a potential of 31.9 million metric tons (MMT) per year in the world [4] and it generally represents a residue not easy upgraded from the thermal point of view due to its high content in silica. This aspect in fact could be a concern when adopting the most common expedient that is the use of residues as boiler fuels. Rice bran has already

\section{Springer}

(c) 2015 Zaccheria et al. This article is distributed under the terms of the Creative Commons Attribution 4.0 International License (http://creativecommons.org/licenses/by/4.0/), which permits unrestricted use, distribution, and reproduction in any medium, provided you give appropriate credit to the original author(s) and the source, provide a link to the Creative Commons license, and indicate if changes were made. The Creative Commons Public Domain Dedication waiver (http://creativecommons.org/ publicdomain/zero/1.0/) applies to the data made available in this article, unless otherwise stated. 
been shown to be a very interesting source of valuable organic compounds. In particular, hydrolysis of the protein fraction can provide ingredients characterized by a good taste profile and by functional properties useful for industrial food processing, storage and consumption [5]. On the other hand, rice bran also contains a non-negligible amount of oil, around 15-25\%, that potentially translates into 6.4 MMT/y [4], an amount comparable to that of other important commodities such as cotton seed and palm kernel oil.

Despite such huge amount, India is the only country producing $65.7 \%$ of its potential $(820,000 \mathrm{MT})$, whereas China and Indonesia still scarcely exploit this source [4]. The actual realized rice bran oil (RBO) is estimated as 1.2 million metric tons, the main barrier to its exploitation being the fast release of free fatty acids. Thus, RBO spontaneously hydrolyses during pick up and processing steps into the corresponding free fatty acids due to the presence of endogenous microbic lipases typically observed in cereals $[6,7]$. Besides different kinds of lipases and phospholipases (A1, A2, B, C, D), also glycolipases and esterases have been identified in rice bran. This aspect strongly limits the use of RBO as edible oil, considering that just within $24 \mathrm{~h}$ after bran pick up great amounts of oil are lost for this purpose due to lipase activity and that free fatty acids content can reach $60 \%$ after 30 days at room temperature [8]. This is also why the rice bran can be used as animal feed only if previously stabilized.

The high free fatty acid (FFA) content is not negligible also in using oils for industrial purposes. In biodiesel production, for example, the homogeneously basic catalyzed transesterification process requests to feed oils with an acidity lower than $0.5 \%$. In this scenario, due to the promising properties of RBO as fuel $[9,10]$ recent researches aim to use a bifunctional catalyst able to promote a simultaneous esterification + transesterification reaction, in order to overcome the high and unstable acidity [11]. Apart from these applications, studies about the possibility to use rice bran oil for the preparation of other oleochemicals are lacking.

Nonetheless, the exploitation of acidic oils as raw materials is becoming even more pressing due to both economic and social reasons. Bioproducts demand from the consumers is indeed a driving force for industrial development. However, also the transformation processes have to be environmentally friendly, particularly as far as the production of wastewaters is concerned.

Following our previous work on the use of amorphous mixed oxides for the esterification of free fatty acids with methanol and polyols for the preparation of biodiesel [12] and biolubricants [13], here we are going to present the application of the same kind of solid acid catalysts in the esterification of rice bran oil with glycerol for the preparation of monoglycerides, valuable products for food and cosmetic formulations, or alternatively the synthesis of triglycerides, useful for power generators, thus allowing to convert an issue, such as the high acidity level, into an opportunity.

\section{Methods}

Rice bran oil has been extracted from rice bran supplied from Riseria Fossati (Fara Novarese, NO, Italy) by using a soxhlet apparatus for $4 \mathrm{~h}$ and heptane as the solvent. The Fatty acid profile was analyzed by GC analysis (HP6890) of the corresponding methylester by using a nonbonded, biscyanopropylpolysiloxane $(100 \mathrm{M})$ capillary column. FFAs content was determined by titration with $\mathrm{NaOH}(0.1 \mathrm{M})$ and phenolphthalein by dissolving the oil in a mixture of 1:2 EtOH/diethylether according to the NGDC10-1976 method. IV was evaluated by titration by using the EN 14111:2003 standard. Oxidation stability was evaluated with the Rancimat method according to CEN TC 307.

Thermogravimetric analysis (TGA) was performed on Perkin Elmer 7 HT thermobalance. Analyses were performed by heating the sample from $50-1000{ }^{\circ} \mathrm{C}$ with a temperature ramp of $5{ }^{\circ} \mathrm{C} / \mathrm{min}$. The water loss was evaluated in the range of $250-900{ }^{\circ} \mathrm{C}$ and $\mathrm{mmol}_{\mathrm{OH}} / \mathrm{g}_{\mathrm{cat}}$ was calculated by the following formula: $[(2 \times \Delta \mathrm{wt} \%) \times 10] / 18$ (g/mol).

Amorphous mesoporous mixed oxides as silicaalumina and silica-titania were used as catalysts. Namely $\mathrm{SiO}_{2}-\mathrm{Al}_{2} \mathrm{O}_{3}\left(13\right.$ wt $\% \mathrm{Al}_{2} \mathrm{O}_{3}, \mathrm{SSA}=485 \mathrm{~m}^{2} / \mathrm{g}$, $\mathrm{PV}=0.79 \mathrm{~mL} / \mathrm{g}$ ) was purchased from Sigma Aldrich; $\mathrm{SiO}_{2}-\mathrm{TiO}_{2}\left(2,3 \% \mathrm{TiO}_{2}, \mathrm{SSA}=297 \mathrm{~m}^{2} / \mathrm{g}, \mathrm{PV}=1.26 \mathrm{~mL} / \mathrm{g}\right)$ were kindly supplied from Grace Davison, Columbia, USA. The catalysts, if not otherwise specified along the text, were used without any thermal pretreatment.

In a typical esterification reaction, the catalyst ( $2 \%$ by weight with respect to the rice bran oil) was charged with rice bran oil (20 g) and glycerol (1,2:1 = glycerol:FFAs for monoglycerides and $1: 3=$ glycerol:FFAs for triglycerides) in a three necked glass flask connected with a Claisen condenser. A slow nitrogen flow was used to better remove the water formed during reaction. The reaction was performed by maintaining the temperature at 170 or $200{ }^{\circ} \mathrm{C}$ with an oil bath and magnetic stirring $(1000 \mathrm{rpm})$. At the end of the reaction $(6 \mathrm{~h})$, the mixture was separated from the catalyst by centrifugation. The ester distribution was determined by GC analysis (Agilent $7890 \mathrm{~N}$ equipped with an on column injector, an AT-1 column, $12 \mathrm{~m} \times 0.32 \times 0.1 \mathrm{~mm})$. Before injection the fatty mixture was derivatized by using $\mathrm{N}, \mathrm{O}$-bis(trimethylsilyl)trifluoroacetamide (BSTFA) together with hexadecane as 
the standard. Catalytic experiments were repeated for three times by observing a standard deviation of $\pm 3 \%$ for mono-, di- and triglycerides distribution and of $\pm 2 \%$ for FFAs conversion.

\section{Results and discussion}

Extraction of the oil from rice bran by using a soxhlet apparatus and heptane as the solvent resulted in a good and reproducible yield if compared to what reported in the literature. Oil yield was found to be in the range of $15-20 \%$ (mean yield $17.1 \pm 1.3$ with \% RSD of 8.0, Table 1) by weight with respect to dry rice bran.

The oil has been characterized both in terms of fatty acid composition and chemical and physical properties, by evaluating parameters described in Table 2 .

Some considerations can be drawn from the data reported in Table 2. Rice bran oil has some interesting features for its use in different applications. In particular it presents a quite high oxidative stability, considering that the Rancimat period is $16.9 \mathrm{~h}$. This aspect has already been highlighted in the literature and ascribed to the presence of significant amount of natural antioxidants such as tocopherols, tocotrienols and oryzanol which are able to prevent lipid oxidation [14]. Peroxide number, expressed as $\mathrm{meq}_{\mathrm{O} 2} / \mathrm{Kg}$ is in the same way quite low. Good properties are also related to the pretty good pour point and to an iodine value of 110 , diagnostic of a moderate presence of double bonds in the fatty acids. Such a low value is mainly ascribable to the presence of a significant amount of the saturated compounds (particularly C16:0, palmitic acid) that counterbalances a quite high amount of linoleic acid (C18:2), that reaches $39.5 \%$, as shown in the fatty acid composition reported in Table 2.

As already mentioned in the introduction, the content in free fatty acids is very high and in our sample resulted to be up to $84 \%$ by weight. Having in hand such a highly acidic oil, we studied the possibility to convert free fatty acids by means of esterification reaction with glycerol to obtain different products.

The use of solid mixed oxides such as $\mathrm{SiO}_{2}-\mathrm{Al}_{2} \mathrm{O}_{3}$, $\mathrm{SiO}_{2}-\mathrm{ZrO}_{2}$ or $\mathrm{SiO}_{2}-\mathrm{TiO}_{2}$ already revealed to be a viable tool in order to obtain esters of fatty acids with methanol. The acidic character of these solid systems, as well as their peculiar resistance to water formed during reaction, allowed us to obtain conversions of $79-91 \%$ in the esterification of acidic mixtures with a starting FFAs content ranging from 1 to $98 \%$ by weight (as was found to be the case of Tall oil Fatty Acids) with methanol after $1 \mathrm{~h}$ at $180{ }^{\circ} \mathrm{C}(10 \%$ by wt of catalyst and methanol/oil $=10: 1)$, thus producing the corresponding methylesters in very good yield [12].

Table 1 Several extraction of rice bran oil have been performed by observing high reproducibility in the oil yield

\begin{tabular}{llllllll}
\hline Entry & Dry bran $(\mathbf{g})$ & Oil $(\mathbf{g})$ & Yield $(\%)$ & Entry & Dry bran $(\mathbf{g})$ & Oil $(\mathbf{g})$ & Yield (\%) \\
\hline 1 & 62.54 & 11.84 & 18.93 & 14 & 193.07 & 35.80 & 18.54 \\
2 & 75.72 & 11.49 & 15.17 & 15 & 201.90 & 38.40 & 19.02 \\
3 & 94.95 & 14.26 & 15.02 & 16 & 201.00 & 37.50 & 18.66 \\
4 & 142.96 & 21.69 & 15.17 & 17 & 250.00 & 42.40 & 16.96 \\
5 & 124.77 & 21.08 & 16.90 & 18 & 250.50 & 20.01 & 19.96 \\
6 & 139.80 & 21.10 & 15.09 & 19 & 251.00 & 43.00 & 17.13 \\
7 & 139.67 & 22.88 & 16.38 & 20 & 237.00 & 20.60 & 17.13 \\
8 & 134.24 & 23.40 & 17.43 & 21 & 207.50 & 33.90 & 16.34 \\
9 & 133.13 & 21.55 & 16.19 & 22 & 212.00 & 37.70 & 17.78 \\
10 & 131.43 & 22.66 & 17.24 & 23 & 207.40 & 34.30 & 16.54 \\
11 & 138.24 & 23.43 & 16.95 & 24 & 242.00 & 47.00 & 19.42 \\
12 & 140.05 & 22.53 & 16.09 & 25 & 250.70 & 41.70 & 16.63 \\
13 & 152.60 & 27.47 & 18.00 & 26 & 205.70 & 33.00 & 16.04 \\
\hline
\end{tabular}

Table 2 The extracted oil has been analyzed by measuring the lodine value (IV), peroxide number, oxidation stability and free fatty acidity (FFA) and by evaluating the fatty acid profile by gas chromatography

\begin{tabular}{|c|c|c|c|c|c|c|c|c|c|}
\hline \multicolumn{5}{|c|}{ Fatty acid composition (\%) } & \multirow{2}{*}{$\begin{array}{l}\text { Pour point }\left({ }^{\circ} \mathrm{C}\right) \\
-15\end{array}$} & \multirow{2}{*}{$\begin{array}{l}\mathrm{IV}\left(\mathbf{g l}_{\mathbf{2}} / 100 \mathrm{~g}\right) \\
110\end{array}$} & \multirow{2}{*}{$\begin{array}{l}\begin{array}{l}\text { Peroxide } \mathrm{N}^{\circ} \\
\left(\mathrm{meqO}_{\mathbf{2}} / \mathrm{Kg}\right)\end{array} \\
0.94\end{array}$} & \multirow{2}{*}{$\begin{array}{l}\begin{array}{l}\text { Oxidation } \\
\text { stability (h) }\end{array} \\
16.9\end{array}$} & \multirow{2}{*}{$\begin{array}{l}\text { FFAs (\%) } \\
84.2\end{array}$} \\
\hline $\mathrm{C} 16: 0$ & $\mathrm{C} 18: 0$ & C18:1 & C18:2 & C18:3 & & & & & \\
\hline 16.8 & 1.6 & 40.2 & 39.5 & 1.9 & & & & & \\
\hline
\end{tabular}


Nonetheless, to obtain esters of acidic oils with alcohols others than methanol is by now an even important target due to the need of using raw and non food oils also for the preparation of different kind of oleochemicals. Moreover, the valorization of waste oils deriving from agro-industries wastes is mandatory for a successful and convenient biorefinery.

First the possibility to obtain monoglycerides has been explored by using glycerol. Thus, fatty acid derived monoglycerides represent important industrial products due to their emulsifying properties [15]. To obtain monoglycerides from rice bran oil is not trivial due to the presence of both free fatty acids and triglycerides in the starting material.

This particular composition requires on one hand the esterification ofthe FFAs fraction and on the other, the transesterification of triglycerides.

Several attempts to produce monoglycerides through the use of lipases, also immobilized, have been reported [16-20]. However, the yield in monoglycerides never exceeded $40 \%$, thus requiring a molecular distillation process. Moreover these enzymes can only be used with refined oils, that is, through transesterification of pure triglycerides. To combine in one single catalyst esterification and transesterification activities, to convert in one step a mixture of free fatty acids and triglycerides, is quite challenging (Scheme 1).

Acidic mixed oxides already showed to promote both esterification and transesterification reaction with methanol, thus allowing us to reduce the acidity of an oil from $5 \mathrm{wt} \%$ to less than $0.5 \mathrm{wt} \%$, while converting at the same time the triglyceride fraction with a final methylester yield of $81.6 \%$ [12]. On the basis of these results, we looked for a similar process in the presence of glycerol. The main results obtained in this transformation are summed up in Fig. 1 and Table 3.
The esterification reaction proceeds with pretty good results, with FFAs conversion values ranging from $87 \%$ to $95 \%$. At the same time, the use of $\mathrm{SiO}_{2}-\mathrm{TiO}_{2}$ reveals the best results in terms of transesterification activity. In fact by using a ratio Gly/FFA of 1.2, that is the one necessary in order to obtain monoglycerides from free fatty acids and triglycerides starting from a mixture containing $84 \%$ of FFAs, it is possible to completely convert the triglycerides into mono- and diglycerides. On the contrary, results obtained in this transformation with $\mathrm{SiO}_{2}$ $\mathrm{Al}_{2} \mathrm{O}_{3}$ are unsatisfying particularly as far as triglycerides conversion is concerned (Fig. 1). The main reason for the difference observed could be ascribed to the acidic character of the catalysts.

The $\mathrm{SiO}_{2}-\mathrm{Al}_{2} \mathrm{O}_{3}$ sample when analyzed by IR spectroscopy of the adsorbed pyridine reveals in fact the co-presence of both Lewis and Brønsted acid sites due to acidic surface $-\mathrm{OH}$ group and $\mathrm{Al}^{3+}$ cations [21]. On the other hand, $\mathrm{SiO}_{2}-\mathrm{TiO}_{2}$ samples analyzed in the same way show a very much weaker acidity with signals ascribable to chemisorbed Py detectable after degassing up to $100{ }^{\circ} \mathrm{C}$.

The higher efficiency of Lewis acids with respect to Brønsted ones in the transesterification of rice bran oil has been already highlighted [22]. Moreover, among different homogeneous Lewis acids, medium-strength ones have been reported as the more effective ones [23]. On the other hand, $\mathrm{Ti}$ catalysts are already known to promote transesterification reactions [24].

It is interesting to note that by using $\mathrm{SiO}_{2}-\mathrm{TiO}_{2}$ catalyst calcined at $270{ }^{\circ} \mathrm{C}$ (entries 5 and 6) before reaction a significant decrease in monoglyceride content was observed. Thermal treatment is actually known to strongly influence the properties of solid catalysts [25], calcination at increasing temperatures allowing to reveal a higher concentration of Lewis acid sites while also reducing the hydrophilicity of the surface in terms of $-\mathrm{OH}$ concentration. The decrease

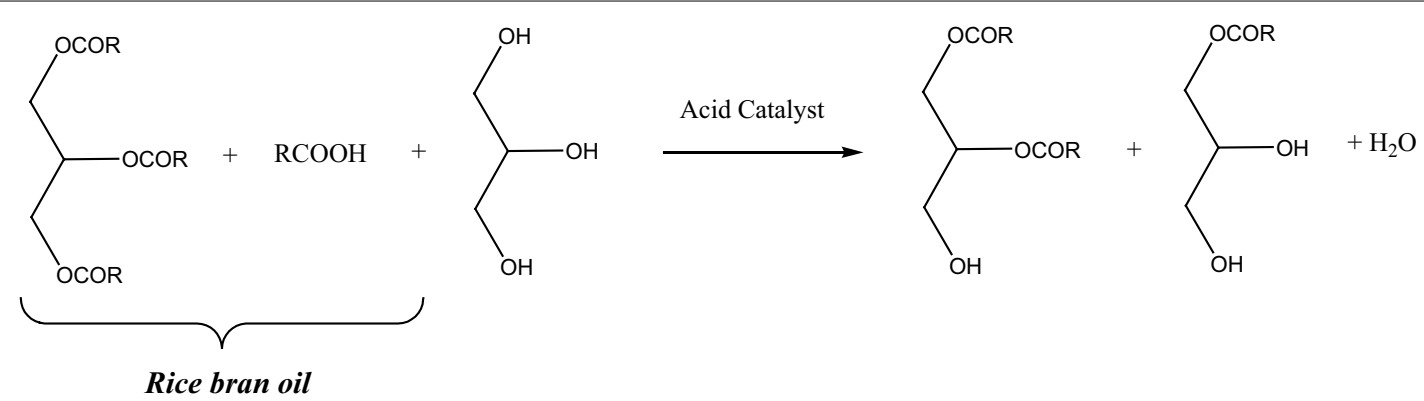

Scheme 1 Reaction of rice bran oil (schematized as the mixture of triglyceride and fatty acid) with glycerol in the presence of an acidic mixed oxide for the preparation of monoglycerides 


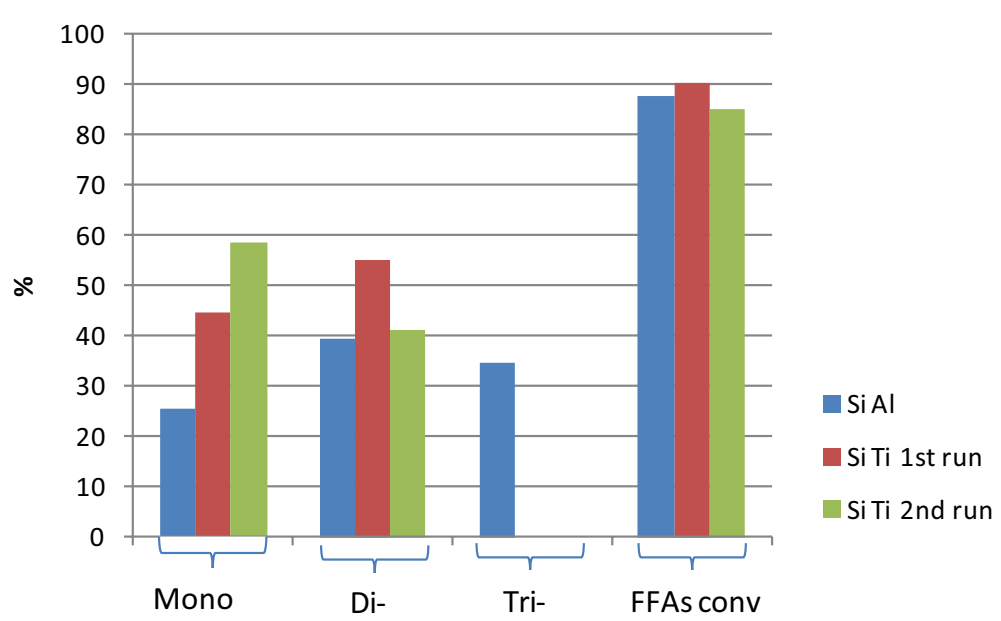

Fig. 1 Distribution of mono-, di- and triglycerides and FFAs conversion after reaction of $\mathrm{RBO}$ with glycerol (1.2 molar ratio) in the presence of $\mathrm{SiO}_{2}$ $\mathrm{Al}_{2} \mathrm{O}_{3}$ and $\mathrm{SiO}_{2}-\mathrm{TiO}_{2}\left(170{ }^{\circ} \mathrm{C}, 6 \mathrm{~h}\right.$, catalyst $=2 \%$ by weight, $84 \% \mathrm{FFAs}, 16 \%$ triglycerides $)$

Table 3 Rice bran oil has been esterified with different amounts of glycerol for the preparation of the corresponding monoglycerides in the presence of $\mathrm{SiO}_{2}-\mathrm{TiO}_{2}$ after $6 \mathrm{~h}\left(\mathrm{~T}=170{ }^{\circ} \mathrm{C}\right.$ catalyst $=2 \%$ by weight, $84 \% \mathrm{FFAs}, 16 \%$ triglycerides $)$

\begin{tabular}{lllllll}
\hline Entry & Catalyst & Gly/FFA & MonoGly (\% mol) & \%DiGly (\% mol) & \%TriGly (\% mol) & FFAs Conv (\%) \\
\hline 1 & $\mathrm{SiO}_{2}-\mathrm{TiO}_{2}$ & $1.2: 1$ & 44.7 & 55.3 & 0.0 & 90.3 \\
2 & $2 \mathrm{nd} \mathrm{run}$ & & 58.8 & 41.2 & 0.0 & 85.4 \\
3 & $\mathrm{SiO}_{2}-\mathrm{TiO}_{2}$ & $2: 1$ & 43.3 & 56.7 & 0.0 & 95.2 \\
4 & $\mathrm{SiO}_{2}-\mathrm{TiO}_{2}$ & $3: 1$ & 42.6 & 57.4 & 0.0 & 93.3 \\
5 & $\mathrm{SiO}_{2}-\mathrm{TiO}_{2}$ act. $^{a}$ & $1.2: 1$ & 32.9 & 67.1 & 0.0 & 93.9 \\
6 & $\mathrm{SiO}_{2}-\mathrm{TiO}_{2}$ act. $^{\text {a }}$ & $2: 1$ & 34.0 & 57.6 & 8.4 & 92.0 \\
\hline
\end{tabular}

a Catalyst calcined at $270^{\circ} \mathrm{C}$ before reaction

in monoglycerides observed by using the same catalyst calcined at higher temperature could therefore be well due to the lower interaction of the catalyst surface with the water formed during reaction, thus allowing the esterification reaction to proceed to a greater extent.

To further increase the yield in monoglycerides, a second catalytic cycle carried out on the stream obtained from entry one in Table 3 allowed us to obtain more than $58 \%$ of monoglyceride.

Monoglycerides are usually synthesized through esterification of the free fatty acid with glycerol in the presence of sulfuric or phosphoric acid at $200-250{ }^{\circ} \mathrm{C}$. Mixtures of mono-, di- and triglycerides are produced that need to be purified by molecular distillation after neutralization and washing steps.

Solid acids such as zeolites and sulfonic resins gave very low conversion in the reaction of oleic acid with glycerol [26] as well as ordered mesoporous materials [27] whereas sulfonic acid modified mesoporous materials allowed to completely convert oleic acid [28] although selectivity was very low for conversions higher than $50 \%$. More recently the use of Sn-metal organic framework and zeolitic imidazolate framework in t-butanol has been proposed for this reaction $[29,30]$. Selectivity to monoglycerides was very high but conversion never exceeded $60 \%$.

Results obtained in the present work are very interesting if we consider that we obtain a mixture of mono- and di-glycerides starting from a mixture of fatty acids and triglycerides. Moreover mixtures with a concentration of $50 \%$ of monoglycerides are already suitable for some purposes and also eligible as proper feed for an efficient molecular distillation, that is the process commonly employed to obtain mixtures with $90 \%$ monoglycerides used in food application [15].

Besides the focus on biomass utilization and bioproducts manufacturing, biorefinery driven technologies have to respond also to other important criteria such as the versatility, diversification of sources and products and process integration. In this scenario, the possibility 
to prepare a range of different products upon need or request starting from the same material has to be envisaged.

In the case of rice bran oil, another important valorization opportunity could be to restore the triglyceride mixture by reaction with a higher amount of glycerol (Scheme 2). In this way the spontaneous hydrolysis of bran oil into FFA can again lead to a material useful as power generator feed. For this purpose triglyceride mixture is needed and FFAs limits are much less restrictive with respect to the standard imposed for biodiesel used in the engines. Thus, power generation feed can also reach $8-9 \%$ of FFAs.

From the data reported in Table 4, it is evident that the use of modified silica allows one to obtain triglycerides from oleic acid and glycerol with excellent yield, particularly in the case of silica-titania. Thus, it is possible to reach a final FFA of $5 \%$ after $6 \mathrm{~h}$ of treatment (Entry 1 ). What is worth underlining is that almost comparable performances can be observed when using rice bran oil as the acidic mixture instead of pure oleic acid, reaching a final FFAs of $7 \%$, even so complying the limits requested for power generators fuel (Entry 3).

On the other hand, taking into account the complex nature of these reactions, based on esterification but also involving components and reagents significantly different in nature, the surface properties of the catalyst could play a major role. In particular the surface hydrophilicity of mixed oxides can influence the interaction, respectively, with free fatty acids, glycerol and mono-, di- and triglycerides. Moreover, the presence of water formed during reaction has to be taken into account.
As already mentioned for monoglycerides preparation, also in this case the surface properties of the different materials seem to have a strong effect. Silica-alumina presents a much higher hydrophilic character with respect to silica-titania $\left(9,25 \mathrm{vs} 2,39 \mathrm{mmol}_{\mathrm{OH}} / \mathrm{g}_{\text {cat }}\right)$ and this aspect could be crucial. The occupation of active acid sites is a competition between fatty acid molecules, glycerol, glycerides and water and the increasing amount of water could hinder the reaction at high conversions [31].

The importance to make biodiesel production costeffective not only by means of upstream strategies, but also with downstream ones has been recently analyzed [32]. The exploitation of glycerol is surely a key point in this context and the possibility of its reuse without any further purification could be an important point to look at.

\section{Conclusions}

$\mathrm{SiO}_{2}-\mathrm{TiO}_{2}$ and $\mathrm{SiO}_{2}-\mathrm{Al}_{2} \mathrm{O}_{3}$ have been shown to be versatile solid catalysts in order to valorise raw rice bran oil for different purposes. In particular $\mathrm{SiO}_{2}-\mathrm{TiO}_{2}$ due to its high resistance to water formed during the esterification reaction, is able to convert up to $90 \%$ of FFAs transesterifying at the same time the triglycerides in the oil. Comparable results were obtained also in the esterification with excess of glycerol to produce an oil suitable for power generation. This shows that processes able to overcome the high acidity of RBO, may be a valuable tool to take advantage of this resource for the production of chemicals, also considering that from defatted bran further extraction of high-value molecules is possible [33]. The possibility to up-value such an important residue

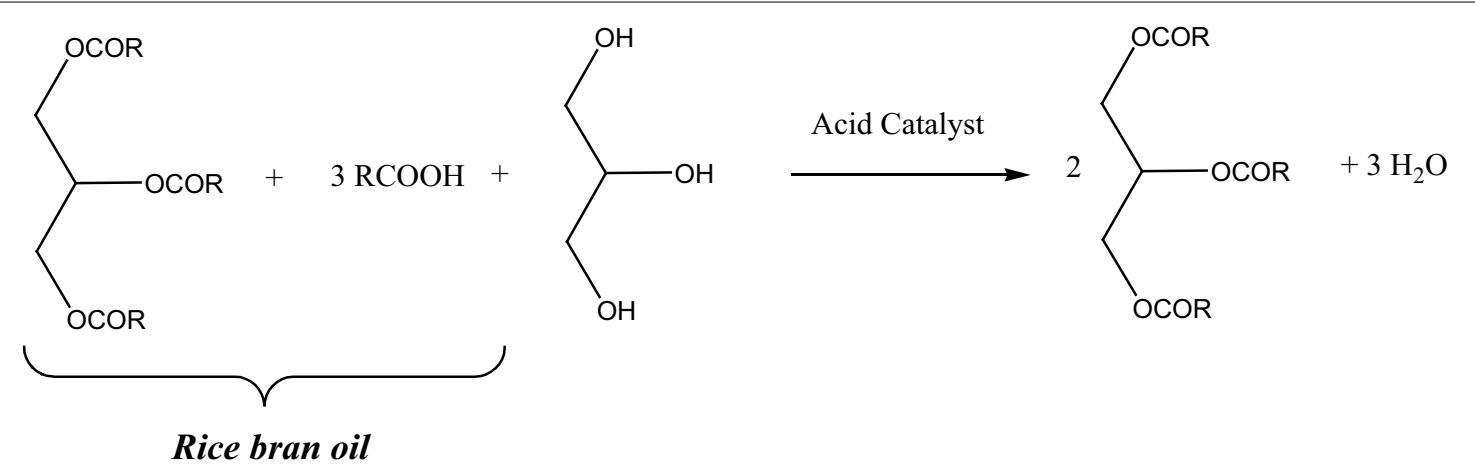

Scheme 2 Reaction of rice bran oil (schematized as the mixture of triglyceride and fatty acid) with glycerol in the presence of an acidic mixed oxide for the preparation of triglycerides 
Table 4 Esterification of Oleic acid and rice bran oil have been performed with glycerol (3:1) in the presence of $\mathrm{SiO}_{2}-\mathrm{TiO}_{2}$ and $\mathrm{SiO}_{2}-\mathrm{Al}_{2} \mathrm{O}_{3}\left(6 \mathrm{~h} ; \mathrm{T}=200{ }^{\circ} \mathrm{C}\right.$, catalyst $=2 \%$ by weight, $84 \%$ FFAs, $16 \%$ triglycerides)

\begin{tabular}{llllcl}
\hline Catalyst & Substrate & $\begin{array}{l}\text { Starting } \\
\text { FFAs (\%) }\end{array}$ & $\begin{array}{l}\text { Final } \\
\text { FFAs (\%) }\end{array}$ & $\begin{array}{l}\text { Conv } \\
\text { (\%) }\end{array}$ \\
\hline 1 & $\mathrm{SiO}_{2}-\mathrm{TiO}_{2}$ & Oleic acid & 100 & 5.0 & 95.0 \\
2 & $\mathrm{SiO}_{2}-\mathrm{Al}_{2} \mathrm{O}_{3}$ & Oleic acid & 100 & 11.0 & 89.0 \\
3 & $\mathrm{SiO}_{2}-\mathrm{TiO}_{2}$ & Rice bran oil & 84.2 & 7.0 & 92.0 \\
4 & $\mathrm{SiO}_{2}-\mathrm{Al}_{2} \mathrm{O}_{3}$ & Rice bran oil & 84.2 & 19.0 & 77.0 \\
\hline
\end{tabular}

merits to be envisaged through different routes, thus giving different opportunities depending on availability and product needs.

\section{Abbreviations}

RBO: rice bran oil; FFA: free fatty acid; IV: iodine value; SSA: specific surface area; $\mathrm{PV}$ : pore volume; TGA: thermo gravimetric analysis.

\section{Authors' contributions}

FZ carried out the catalytic reactions and the data analysis and drafted the manuscript. MM carried out the extraction and analysis of the oil. NR conceived the study and coordinated the work. All authors read and approved the final manuscript.

\section{Acknowledgements}

Authors acknowledge Cariplo Foundation for funding the project 2014-0558 "RiceRes" and COST Action TD1203 EUBis "Food waste valorization for sustainable chemicals, materials\&fuels".

\section{Competing interests}

The authors declare that they have no competing interests.

Received: 10 September 2015 Accepted: 12 November 2015

Published online: 22 December 2015

\section{References}

1. Lin CSK, Koutinas AA, Stamatelatou K, Mubofu EB, Matharu AS, Kopsahelis N, Pfaltzgraff LA, Clark JH, Papanikolaou S, Kwan TH, Luque R. Current and future trends in food waste valorization for the production of chemicals, materials and fuels: a global perspective. Biofuels Bioprod Bioref. 2014:8(5):686-715.

2. Lin CSK, Pfaltzgraff LA, Herrero-Davila L, Mubofu EB, Abderrahim S, Clark JH, Koutinas AA, Kopsahelis N, Stamatelatou K, Dickson F, Thankappan S, Mohamed Z, Brocklesby R, Luque R. Food waste as a valuable resource for the production of chemicals, materials and fuels. Current situation and global perspective. Energy Environ Sci. 2013;6:426-64.

3. Pfaltzgraff LA, De Bruyn M, Cooper EC, Budarin V, Clark JH. Food waste biomass: a resource for high-value chemicals. Green Chem. 2013;15:307-14.

4. Gopala Krishna AG. Rice bran oil: nature's healthful oil. Inform. 2013:24(4):260-5.

5. Bagnasco L, Pappalardo VM, Meregaglia M, Kaewmanee T, Ubiali D, Speranza G, Cosulich ME. Use of food-grade proteases to recover umami protein-peptide mixtures from rice middlings. Food Res Int. 2013;50:420-7.

6. Takano K. Mechanism of lipid hydrolysis in rice bran. Cereal Foods World. 1993:38(9):695-8

7. Brunschwiler C, Heine D, Kappeler S, Conde-Petit B, Nyström L. Direct measurement of rice bran lipase activity for inactivation kinetics and storage stability prediction. J Cereal Sci. 2013;58:272-7.
8. Prabhakar DS, Anil Kumar HG, Gopala Krishna AG. Process for retardation of free fatty acids development and retention of inherent antioxidants in rice bran and the extracted oil. J Lipid Sci Technol. 2010;42(2):56-63.

9. El Boulifi N, Bouaid A, Martinez M, Aracil J. Optimization and oxidative stability of biodiesel production from rice bran oil. Renew Energy. 2013;53:141-7

10. Evangelista JPC, Chellappa T, Coriolano ACF, Fernandes VJ Jr, Souza LD Araujo AS. Synthesis of alumina impregnated with potassium iodide catalyst for biodiesel production from rice bran oil. Fuel Process Technol. 2012;104:90-5.

11. Zhang Y, Wong WT, Yung KF. One-step production of biodiesel from rice bran oil catalyzed by chlorosulfonic acid modified zirconia via simultaneous esterification and transesterification. Bioresour Technol. 2013;147:59-64.

12. Zaccheria F, Brini S, Scotti N, Psaro R, Ravasio N. Esterification of acidic oils over a versatile amorphous solid catalyst. ChemSusChem. 2009;2(6):535-7.

13. Zaccheria F, Mariani M, Psaro R, Bondioli P, Ravasio N. Environmentally friendly lubricants through a zero waste process. Appl Catal B Environ. 2016;181:581-6.

14. Adhikari P, Shin JA, Lee JH, Kim HR, Kim IH, Hong ST, Lee KT. Crystallization, physicochemical properties, and oxidative stability of the interesterified hard fat from rice bran oil, fully hydrogenated soybean oil, and coconut oil through lipase-catalyzed reaction. Food Bioprocess Technol. 2012:5:2474-87.

15. Fregolente LV, Batistella CB, Filho RM, Wolf-Maciel MR. Optimization of distilled monoglycerides production. Appl Biochem Biotechnol. 2006;129:680-93.

16. Ferreira-Dias S, da Fonseca MMR. Production of monoglycerides by glycerolysis of olive oil with immobilized lipases: effect of the water activity. Bioprocess Eng. 1995; 12:327-37

17. Noureddini H, Harmeier SE. Enzymatic glycerolysis of soybean oil. JAOCS 1998;75:1359-65 (and refs therein)

18. Elfman-Börjesson I, Harröd M. Synthesis of monoglycerides by glycerolysis of rapeseed oil using immobilized lipase. JAOCS. 1999;76:701-7.

19. Rendón X, López-Munguía A, Castillo E. Solvent engineering applied to lipase-catalyzed glycerolysis of triolein. JAOCS. 1061;2001:78.

20. Fregolente PBL, Pinto GMF, Wolf-Maciel MR, Filho RM. Monoglyceride and diglyceride production through lipase-catalyzed glycerolysis and molecular distillation. Appl Biochem Biotechnol. 2010;160:1879-87 (and refs therein).

21. Mariani M, Zaccheria F, Psaro R, Ravasio N. Some insight into the role of different copper species as acids in cellulose deconstruction. Catal Commun. 2014:44:19-23.

22. Einloft S, Magalhães TO, Donato A, Dullius J, Ligabue R. Biodiese from rice bran oil: transesterification by tin compounds. Energy Fuels. 2008;22:671-4.

23. Di Serio M, Tesser R, Dimiccoli M, Cammarota F, Nastasi M, Santacesaria E. Synthesis of biodiesel via homogeneous Lewis acid catalyst. J Mol Catal A Chem. 2005:239:111-5.

24. Sharma RV, Baroi C, Dalai AK. Production of biodiesel from unrefined canola oil using mesoporous sulfated Ti-SBA-15 catalyst. Catal Today. 2014;237:3-12.

25. Ward JW. The nature of active sites on zeolites: $\mathrm{VI}$. The influence of calcination temperature on the structural hydroxyl groups and acidity of stabilized hydrogen Y zeolite. J Catal. 1968;11(3):251-8.

26. Abro S, PouillouxY, Barrault J. Selective synthesis of monoglycerides from glycerol and oleic acid in the presence of solid catalysts. Stud Surf Sci Catal. 1997:108:539.

27. Pérez-Pariente J, Dìaz I, Mohino F, Sastre E. Selective synthesis of fatty monoglycerides by using functionalized mesoporous catalysts. Appl Catal A General. 2003;254:173-88.

28. Diaz I, Mohino F, Blasco T, Sastre E, Pérez-Pariente J. Influence of the alky chain length of $\mathrm{HSO}_{3}-\mathrm{R}-\mathrm{MCM}-41$ on the esterification of glycerol with fatty acids. Microp Mesop Mat. 2005:80:33-42.

29. Wee LH, Lescouet T, Ethiraj J, Bonino F, Vidruk R, Garrier E, Packet D, Bordiga S, Farrusseng D, Herskowitz M, Martens JA. Hierarchical Zeolitic Imidazolate Framework-8 catalyst for monoglyceride synthesis. ChemCatChem. 2013;5:3562-6.

30. Wee LH, Lescouet T, Fritsch J, Bonino F, Rose M, Sui Z, Garrier E, Packet D, Bordiga S, Kaskel S, Herskowitz M, Farrusseng D, Martens JA. Synthesis of monoglycerides by esterification of oleic acid with glycerol in 
heterogeneous catalytic process using tin-organic framework catalyst. Catal Lett. 2013;143:356-63.

31. Grecea ML, Dimian AC, Tanase S, Subbiah V, Rothenberg G. Sulfated zirconia as a robust superacid catalyst for multiproduct fatty acid esterification. Catal Sci Technol. 2012;2:1500-6.
32. Hasheminejad M, Tabatabaei M, Mansourpanah Y, Khatami M, Javani A. Upstream and downstream strategies to economize biodiesel production. Bioresour Technol. 2011;102:461-8.

33. Han SW, Chee KM, Cho SJ. Nutritional quality of rice bran protein in comparison to animal and vegetable protein. Food Chem. 2015;172:766-9.

\section{Submit your manuscript to a SpringerOpen ${ }^{\odot}$} journal and benefit from:

- Convenient online submission

- Rigorous peer review

- Immediate publication on acceptance

- Open access: articles freely available online

- High visibility within the field

- Retaining the copyright to your article

Submit your next manuscript at $\gg$ springeropen.com 